\title{
Transitioning to Open Access: An Evaluation of the UK Springer Compact Agreement Pilot 2016-2018
}

\section{Mafalda Marques and Graham Stone}

\begin{abstract}
This article analyzes the UK's first "read and publish" journals agreement. The Springer Compact Agreement pilot ran from 2016 to 2018. The authors outline the methodology and data sources used to undertake a detailed analysis of the agreement. This includes the number of open access articles published, the number of author opt-outs and rejected articles. Institutional savings (or cost avoidance), and the financial implications resulting from the number of opt-outs and rejected articles are also discussed. The value of articles published and cost per download for non-OA content are also covered. The agreement, at the consortia level, has constrained the total cost of publication-during the three years, the HE sector has avoided paying additional costs of $€ 20,000,800(\$ 22,761,688)$ for publishing OA by paying the single combined fee that capped publication costs at 2014 rates. All institutions taking part in the Springer Compact agreement published OA articles equivalent to or in excess of their total 2014 APC spend between 2016 and 2018. By 2018, 30 percent of institutions published OA articles to the value of or in excess of the combined fee paid to Springer. The article concludes with a number of recommendations for future agreements and considers compliance with Plan $\mathrm{S}$ guidelines.
\end{abstract}

\section{Introduction}

In March 2015, Jisc Collections, which negotiates and licenses digital content agreements to support academic research, teaching, and learning in the UK, announced that it had reached an agreement with Springer (now Springer Nature) for the UK's first "read and publish" agreement, which aimed to contain the costs of publication and subscription access for UK institutions. This article provides an analysis of the three years of the Springer Compact pilot agreement.

Prior to the Springer Compact agreement, institutions paid an annual subscription fee with additional payments for Article Processing Charges (APCs) in Springer's hybrid journals. APC expenditure was increasing year to year. Under the pilot agreement, fees that previously paid for subscriptions (the license fee) were rerouted to pay for publishing in Springer hybrid journals, while an additional reading fee covered the cost of ongoing access and use of subscribed journal content under a database style model with harmonized postcancellation rights.

Geshuhn and Stone ${ }^{1}$ define offset agreements as an "attempt to link article publishing charges (APCs) with subscription charges, looking to increase one while the other reduces.

Mafalda Marques is a Research Analyst, Jisc; email: Mafalda.Marques@jisc.ac.uk. Graham Stone is Senior Research Manager, Jisc; email: Graham.Stone@jisc.ac.uk. (02020 Mafalda Marques and Graham Stone, AttributionNonCommercial (https://creativecommons.org/licenses/by-nc/4.0/) CC BY-NC. 
Some such agreements reduce the APC charge, some allow unlimited open access (OA) publishing for a capped amount and others provide a refund or publishing credit. Offsetting is therefore an advancement of the publishers' hybrid model, which has been criticized because of its 'double-dipping' practice" (see also Bjork for an explanation of double dipping2). Lawson defines offsetting as "recognizing the total spend that an institution makes...the 'total cost of ownership'."'3 Offsetting was first introduced by the Institute of Physics Publishing in 2014.

In the UK, Lawson estimated that the combined value of offsetting agreements between 2015 and 2017 was $£ 19.5 \mathrm{~m}$. Rather than a saving, Lawson considers this as "cost avoidance," as there is no guarantee that all institutions would have chosen to pay the APCs for all articles. In his evaluation of UK offsetting agreements, Lawson concluded that "[o]ffsetting has produced real benefits for higher education institutions by increasing the value of journal license agreements and raising the number of journal articles that are published open access." 4

Schimmer, Geschuhn, and Vogler ${ }^{5}$ regard the hybrid model as an evolutionary step, where offsetting is part of the journey to transform the underlying business model to open access. By 2018, many new big-deal agreements were regarded as offset agreements, the Springer Compact agreement being one of them. ${ }^{6}$ However, both Earney ${ }^{7}$ and Lawson ${ }^{8}$ warn that offsetting agreements have significant drawbacks, are "clearly far from proven," and could even be contradictory to the objectives of OA by becoming business as usual rather than an evolutionary step.

This has been recognized by cOAlition $S$, which calls for an end to hybrid agreements unless they show a transition to open access in new transformational agreements. ${ }^{9}$ These agreements are being called "read and publish" agreements. Earney ${ }^{10}$ defines this as an agreement "where, for a fee, an institution will have access to a publisher's content as well as having all of their authors' articles made OA on publication."

Read and publish models have been devised to enable:

1. A publisher to transfer titles from a hybrid business model to an OA business model by maintaining a level of income. The idea is that, as more and more articles within a journal title are published under an OA model, the easier it is for a publisher to flip that title to 100 percent gold OA and remove the subscription fee.

2. A country or consortia to properly manage and contain the total costs paid by its subscribers/members, particularly additional APC costs, which are rising in number of APCs and expenditure, but also by average cost of an individual APC. ${ }^{11}$ Read and publish models should constrain those costs and ideally enable institutions to offset their costs. At a consortia level, the total combined fee paid to the publisher is set and any price increases are agreed. Indeed, further research has indicated that offsetting agreements are helping to keep inflationary costs down. ${ }^{12}$

3. Institutions to transfer spend on subscriptions to OA publication. This is done through payment of the combined fee, which is split into the read fee and the publishing fee. Over the term of the agreement, the amount allocated to pay for reading should reduce, and the amount allocated to pay for publishing should increase.

The transition to open access as part of the principles of cOAlition $S$ is not just restricted to Europe. In 2018, MIT and the Royal Society of Chemistry signed the first North American read and publish agreement. ${ }^{13}$ This was followed in 2019 by a negotiation's toolkit for North American libraries published by the University of California's Scholarly Communications Office. The toolkit is aimed to help libraries wishing to transform "traditional" subscription agreements to more open purchasing models. ${ }^{14}$ 
Although negotiated as an offset agreement, the Springer Compact pilot is essentially a read and publish model. It aimed to move away from the historical print model and enables researchers from participating UK institutions to publish their articles immediately on OA in more than 1,700 Springer Open Choice hybrid journals ${ }^{15}$ as well as to access all content published in 2,377 Springer journals. ${ }^{16}$ It aimed to reduce cost and administration barriers by allowing all UK articles published in eligible Springer Open Choice hybrid journals to be made OA immediately upon publication. This assists institutions with compliance for existing funder requirements and reduces the burden of having to reallocate funds from research grants to pay for an APC, as these are already covered by the combined fee.

In addition to the UK, a further four national consortia and the Max Planck Digital Library (MPDL) in Germany had similar agreements with Springer. Each of the six agreements regularly send their data through to OpenAPC at Bielefeld University in Germany. ${ }^{17}$ This assists in making information about the articles published openly available from a central resource (see table 1 ).

\begin{tabular}{|c|c|c|c|}
\hline Number of Ins & $\begin{array}{r}\text { tutions in Spri } \\
\mathrm{Ar}\end{array}$ & $\begin{array}{l}\text { TABLE } 1 \\
\text { Compact Agreement by Co } \\
\text { Published (2016 to 2018) }\end{array}$ & rtia and Number of OA \\
\hline Country & Year & \# Institutions in Agreement & \# OA Articles Published \\
\hline Austria & 2016 & 34 & 1,013 \\
\hline & 2017 & 34 & 1,063 \\
\hline & 2018 & 34 & 1,255 \\
\hline Germany (MPDL) & 2016 & 83 & 185 \\
\hline & 2017 & 83 & 392 \\
\hline & 2018 & 83 & 335 \\
\hline Netherlands & 2016 & 39 & 2,094 \\
\hline & 2017 & 39 & 2,073 \\
\hline & 2018 & 39 & 2,042 \\
\hline Sweden & 2016 (Jul-Dec) & 40 & 528 \\
\hline & 2017 & 40 & 1,393 \\
\hline & 2018 & 40 & 1,461 \\
\hline UK & 2016 & 90 & 3,085 \\
\hline & 2017 & 93 & 3,819 \\
\hline & 2018 & 95 & 4,001 \\
\hline Data source: Cons & tia data, OpenA & & \\
\hline
\end{tabular}

A number of interim reports have been published by these consortia, in addition to the UK. ${ }^{18}$ Most notably, the Swedish consortia, BIBSAM, have produced four interim reports, the last two written in English. ${ }^{19}$ Olsson notes that the agreement has increased OA publications and involves less administration. However, the agreement increased the total cost of publication and promotes hybrid over gold OA.

This article will build on previous literature by analyzing the full term of the UK Springer Compact Agreement before making a number of recommendations for future read and publish agreements. 


\section{Data Sources and Methodology}

The UK pilot agreement was monitored for its effectiveness against three core aims. These were decided after extensive consultation with institutions and negotiations with Springer:

- To contain the costs of publication and subscription access for institutions

- To reduce cost and administration barriers to hybrid OA publishing

- To increase the number of funder compliant OA articles.

The agreement began with 90 institutions in 2016, three more joined in 2017, and by 2018 there were 95. Institutions joining in 2017 or 2018 do not feature in previous years' data. An institution's annual fee was calculated on the value of its 2014 hybrid APCs (€) plus the value of their 2015 big deal costs (€) (including their 2015 Adis subscription ${ }^{20}$ ). This fee is referred to as the "combined fee." The total cost of the agreement across the three years was $€ 32,962,488(\$ 37,512,593)$, of which $€ 2,792,177(\$ 3,177,606)(8 \%$ of the combined fee) represented the read element and $€ 30,170,311(\$ 34,334,987)(92 \%)$ represented the publish element. The total value of OA articles published during the agreement was $€ 23,914,600$ $(\$ 27,215,745) .^{21}$

Data provided by Springer has been verified by Jisc Collections. Jisc Collections data on the combined fee was analyzed to calculate the costs incurred and the cost avoidance made by institutions. Usage data from Jisc's Journals Usage Statistics Portal (JUSP) ${ }^{22}$ was analyzed to calculate cost per download (CPD). Frontfile usage (either institutional or title frontfile usage) is calculated by deducting COUNTER Release 4 JR1a (Number of Successful Full-Text Article Requests from an Archive by Month and Journal) usage from JR1 (Number of Successful Full-Text Article Requests by Month and Journal). Subscribed usage is calculated by deducting JR1 GOA (Number of Successful Gold Open Access Full-Text Article Requests by Month and Journal) usage from frontfile usage (that is, JR1-JR1a-JR1 GOA). ${ }^{23}$

The methodology used to evaluate the Springer Compact agreement focused on three principles:

1. An evaluation of the number of articles published by month, article type, institution, main discipline, and journal. The same process was used to assess the number of author opt-outs and rejected articles (see below)

2. An evaluation of the APCs' overall value and their value per institution. In addition, two calculations were made to assess cost avoidance for APCs and the combined fee.

a. APC cost avoidance by institution was calculated by subtracting the total value of APCs for articles published in 2016-2018 by university X ( $€$ ) from the value of the hybrid APCs published by university X in 2014 (€). Institutions that published more OA articles annually (2016, 2017, or 2018) than their 2014 hybrid APC spend have "offset" their APC expenditure. For Example: university X's 2018 articles published (€96,000 [\$109,252]) - the value of the 2014 hybrid APCs $(€ 4,400[\$ 5,007])=€ 91,600(\$ 104,244)$ in 2018 APC cost avoidance

b. The second calculation assessed if institutions had made overall savings on their combined fee based on the number of articles published. The calculation was based on subtracting the total value of an institution's 2016-2018 APCs from their 2016-2018 combined fee. The resulting data indicated whether institutions have "flipped" the agreement to OA, by publishing OA articles that are equivalent to or higher than the total cost of their Springer Compact agreement. 
3. CPD figures were first calculated by measuring usage for "subscribed titles" for each institution, against the subscription or "read" element of the combined fee. This includes all articles published OA regardless of whether they are UK authors or not, such as those articles made OA as part of other international agreements or previous APCs paid prior to the agreement (this would be the case for any CPD calculation). To calculate the adjusted CPD, the value of APCs published above the 2014 spend was deducted from the subscription costs. Therefore, institutions that offset the whole agreement, such as the value of APCs above the 2014 spend was greater than the subscription costs, had an adjusted CPD of $€ 0.00$. It was not possible to calculate CPD for three institutions.

This article refers to author opt-outs and rejected articles. Author opt-outs are articles where the corresponding author has opted out of making their article OA even though they are affiliated with a UK institution participating in the agreement. Rejected articles are those that have been rejected by institutions due to author ineligibility. For example, the author was not listed as a member of that institution at the time of publication. It does not imply that the article was rejected at the peerreview stage. Both author opt-outs and rejected articles have still been published but are behind a paywall.

Data containing confidential information regarding university spend cannot be shared. However, article metadata is shared with the OpenAPC initiative. ${ }^{24}$ The Springer Compact agreement is also available at the ESAC (Efficiency and Standards for Article Charges) agreement registry. ${ }^{25}$

\section{Data Analysis}

The three core aims were analyzed to observe publishing levels, usage, funder compliance, and effectiveness of the pilot in constraining costs for institutions as well as reducing administrative barriers.

\section{OA Publications}

It was observed that the number of articles published OA increased during the lifetime of the agreement. There was a 23.8 percent increase in OA articles published between 2016 and 2017 and a 4.8 percent increase between 2017 and 2018 (see figure 1).

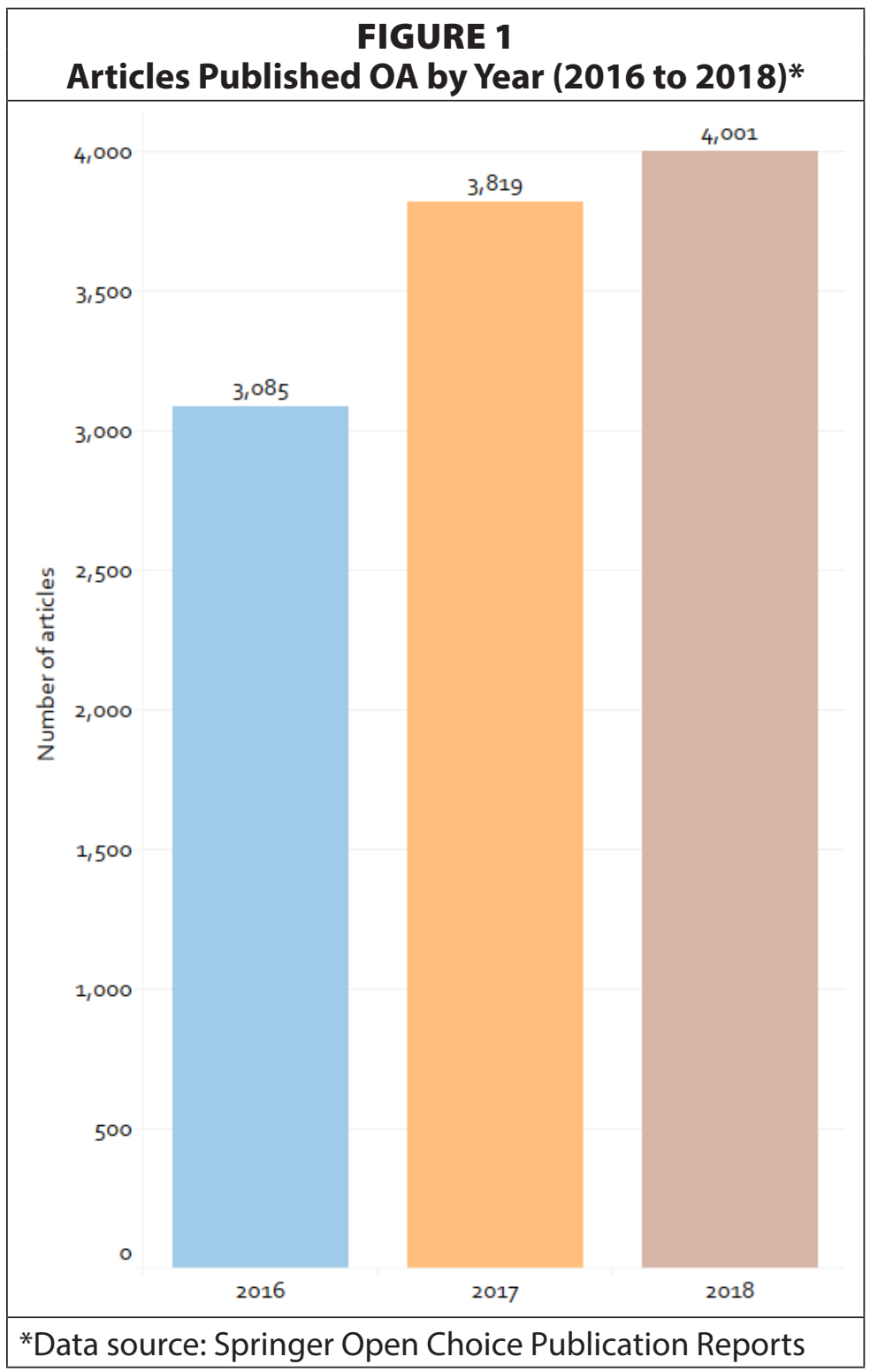


Overall, 10,905 OA articles were published between 2016 and 2018. There has also been an annual increase in OA article publications within the Springer titles. In 2016, the number of articles published OA represented 55.9 percent of the total articles published in all Springer titles by eligible UK authors. This increased to 72.7 percent in 2017 and 74.4 percent in 2018. In 2015, the year before the pilot, the number of articles published OA represented 23 percent of all articles published in Springer titles.

No participating institution has published fewer OA articles than they did in 2014. A total of 97.8 percent of the institutions published OA articles in 2016, 95.7 percent in 2017, and 96.8 percent in 2018. Indeed, only two institutions did not publish any articles across the three-year agreement, a further two did not publish any articles in 2017, and one in 2018. However, they did not publish in the year before the agreement either.

Figure 2 shows the 18 institutions that published more than 50 articles in each year. These institutions published 61 percent of all articles published OA throughout the agreement $(6,669$ articles).

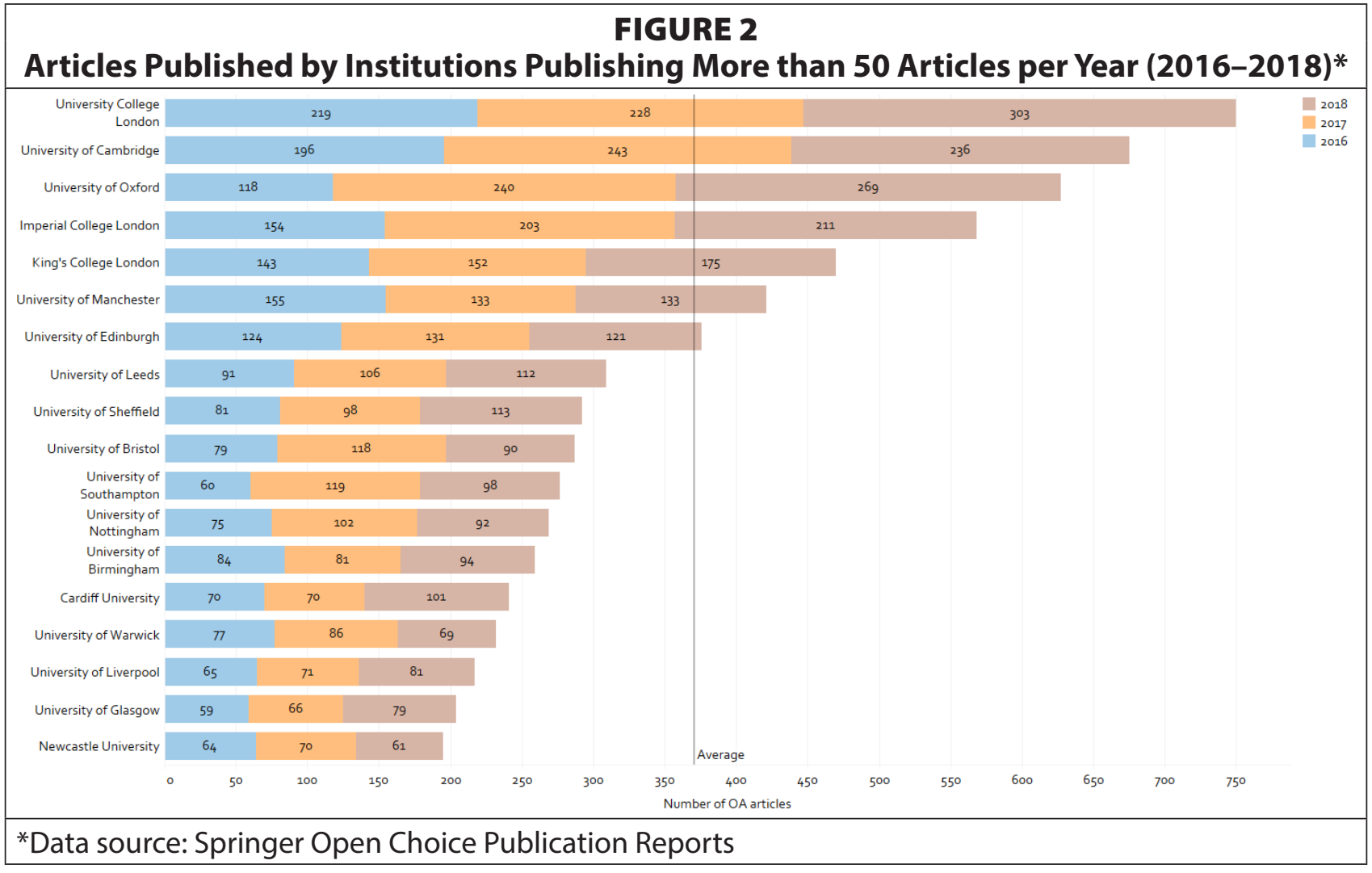

TABLE 2

Data for Eligible and Noneligible Journals (2016 to 2018)

\begin{tabular}{|l|c|c|c|c|}
\hline Year & $\begin{array}{l}\text { Number of Eligible } \\
\text { Journals (Hybrid } \\
\text { Open Choice) }\end{array}$ & $\begin{array}{l}\text { Number of } \\
\text { Noneligible } \\
\text { Journals }\end{array}$ & $\begin{array}{l}\text { Percentage of } \\
\text { Eligible Journals } \\
\text { with OA Articles }\end{array}$ & $\begin{array}{l}\text { Number of OA Articles } \\
\text { Published in Eligible Journals }\end{array}$ \\
\hline 2016 & 1,712 & 521 & $54 \%$ & 3,085 \\
\hline 2017 & 1,788 & 653 & $55 \%$ & 3,819 \\
\hline 2018 & 1,939 & 540 & $54 \%$ & 4,001 \\
\hline \multicolumn{5}{|l}{ Data source: Springer Open Choice Publication Reports and JUSP. } \\
\hline
\end{tabular}


Table 2 shows the number of journal titles that were eligible for OA articles as part of the pilot. The number of hybrid Open Choice titles available has been increasing during the agreement, although the overall percentage of journals with $\mathrm{OA}$ articles has been static.

All articles submitted by corresponding authors affiliated with a participating UK institution are eligible for $\mathrm{OA}$ as part of the agreement. However, authors were given the opportunity to opt out of making their article OA at the article acceptance stage. This was not seen as a particular issue at the outset of the agreement. However, between 2016 and 2018, authors from 86 institutions opted out from publishing some of their articles OA. A total of 39 institutions had 20 or more opt-outs across the three years. In most cases, the institutions with the highest number of OA articles published also had the highest number of opt-outs. Table 3 shows that, put into context with the other pilot agreements, the UK had a particularly high opt-out rate at the start of the pilot. Data was not available for all years for Austria and MPDL. The Dutch and Swedish agreements did not include an author opt-out option.

\begin{tabular}{|c|c|c|c|}
\hline \multicolumn{4}{|c|}{$\begin{array}{l}\text { TABLE } 3 \\
\text { Number of Opt-outs by Consortia and Opt-outs as Percentage of Articles Published OA } \\
\text { (2016 to 2018) }\end{array}$} \\
\hline Country & Year & \# Opt-outs & \% Opt-outs \\
\hline \multirow[t]{3}{*}{ Austria } & 2016 & 180 & $18 \%$ \\
\hline & 2017 & 168 & $16 \%$ \\
\hline & 2018 & $\mathrm{n} / \mathrm{a}$ & $\mathrm{n} / \mathrm{a}$ \\
\hline \multirow[t]{3}{*}{ Germany (MPDL) } & 2016 & 29 & $16 \%$ \\
\hline & 2017 & $n / a$ & $n / a$ \\
\hline & 2018 & $n / a$ & $n / a$ \\
\hline \multirow[t]{3}{*}{ Netherlands } & 2016 & \multirow{3}{*}{ not applicable } & \multirow{3}{*}{ not applicable } \\
\hline & 2017 & & \\
\hline & 2018 & & \\
\hline \multirow[t]{3}{*}{ Sweden } & 2016 (Jul-Dec) & \multirow{3}{*}{ not applicable } & \multirow{3}{*}{ not applicable } \\
\hline & 2017 & & \\
\hline & 2018 & & \\
\hline \multirow[t]{3}{*}{ UK } & 2016 & 1,063 & $35 \%$ \\
\hline & 2017 & 699 & $18 \%$ \\
\hline & 2018 & 683 & $17 \%$ \\
\hline
\end{tabular}

Opt-outs for the UK did decrease in 2017 and 2018. Indeed, a decrease was observed for 57 percent of institutions in 2017 and/or 2018. Conversely, 12 percent of institutions increased the number of opt-outs in 2018 when compared to 2016 and/or 2017. It was also observed that the top seven institutions by "highest number of OA articles published" and "opt-outs between 2016 and 2018" all had Green OA policies. ${ }^{26}$

Regarding titles, UK authors opted out of OA in 881 journals between 2016 and 2018. A total of 79 of these journals had no other OA articles published in them by UK lead authors. If those articles had been published OA, the number of journal titles with OA publications would have increased from 1,456 to 1,536, or 79 percent of available journals by $2018(1,939)$. 
Data on author opt-outs must be taken into consideration when evaluating the potential value of the agreement, specifically the additional cost avoidance that could have been made. As noted in table 3, some agreements do not give authors the option to opt out.

After consultation with the community in 2017, institutions reported that the main reasons for opt-outs related to a lack of understanding among authors about how the process worked. For example, authors thought they may need to pay a fee, were confused about different OA schemes and Springer's brands (Springer Open, Springer Open Choice), and were unclear of the wording of Springer's message on opt-outs. ${ }^{27}$ As a result, significant changes were made to the "My Publication" online article submission and acceptance process, and this may have contributed to the drop in the number of opt-outs. Additionally, seven UK institutions chose to have the opt-out option removed.

Regarding those articles that have been rejected by institutions due to author ineligibility, only 454 articles ( $4.2 \%$ of all the articles published OA) were rejected over the three years. There is no discernible pattern across institutions, and the numbers are very small. This supports the evidence from Sweden, which had a rejection rate of less than 5 percent. ${ }^{28}$

\section{Usage}

It is difficult to draw any meaningful conclusions from usage data alone (see table 4). During the agreement period, the number of eligible titles has increased annually, but usage (for all UK institutions) has fluctuated. In contrast, GOA usage for the whole consortia has been increasing annually since 2016.

\begin{tabular}{|l|c|c|c|}
\hline \multicolumn{4}{|c|}{ TABLE 4 } \\
Usage Data for Springer Compact Journals (2016 to 2018) \\
\hline Year & $\mathbf{2 0 1 6}$ & $\mathbf{2 0 1 7}$ & $\mathbf{2 0 1 8}$ \\
\hline Number of Eligible Titles & 1,712 & 1,788 & 1,939 \\
\hline Eligible Titles Frontfile Usage & $12,225,949$ & $10,376,813$ & $17,209,684$ \\
\hline Eligible Titles GOA Usage & 784,672 & $1,678,759$ & $1,707,552$ \\
\hline Data source: Springer Open Choice titles lists and JUSP. \\
\hline
\end{tabular}

A mere 15 titles accounted for 11.4 percent of the total number of articles published in the three years (1,239 articles). When comparing these 15 titles against JUSP usage data, it was observed that The Journal of Business Ethics had the highest subscribed usage and was in the top 10 for GOA usage. This title also had the fourth highest opt-outs in the agreement (21 articles between 2016 and 2018).

It appears that, overall, titles with the highest number of OA articles were not necessarily the most-read titles by UK institutions. However, the global usage of OA articles published by UK-based authors in these titles was high, which might indicate the potential reach of OA articles via this agreement. Unfortunately, data on global usage for all (OA and paywall) UKauthored articles was not provided by Springer, so the full reach of OA articles is not known.

\section{Article Processing Charges (APCs)}

Containing the costs for publishing was one of the core objectives of the Springer Compact agreement. To understand any potential savings (or cost avoidance), it is important to look 
at the APC value of articles published in the agreement against the "publish" costs in the agreement and against the mean APC (approx. $£ 1,700) .{ }^{29}$

However, external factors also affected any interpretation. Although the cost of APCs during the agreement remained fixed at $€ 2,200(\$ 2,504),{ }^{30}$ the volatility in the exchange rate ${ }^{31}$ meant that the value of the Springer APC in pounds sterling was under the mean APC value at the start of the agreement but finished above the mean in January 2019 (see table 5). Therefore, the value in Euros was used for evaluation.

\begin{tabular}{|l|c|c|}
\hline \multicolumn{2}{c|}{ TABLE 5 } \\
\multicolumn{2}{|c|}{ Springer Compact APC Conversion Table (Euros to Sterling) } \\
\hline Year & Springer Compact APC (Euros) & Springer Compact APC (Sterling) \\
\hline 2016 & $€ 2,200(\$ 2,504)$ & $£ 1,676$ \\
\hline 2017 & $€ 2,200(\$ 2,504)$ & $£ 1,867$ \\
\hline 2018 & $€ 2,200(\$ 2,504)$ & $£ 1,951$ \\
\hline
\end{tabular}

In 2014, 58 institutions incurred a total hybrid APC expenditure of $€ 1,304,600(\$ 1,484,686)$ with an average 2014 APC expenditure per institution of $€ 22,493(\$ 25,598)$. This APC expenditure was in addition to their subscription fee. Under Springer Compact, the single fee combined both their 2015 subscription fee and their 2014 APC expenditure but on the condition that no further APC fees would be charged-essentially enabling an institution to have unlimited OA publishing at the same cost as previously paid.

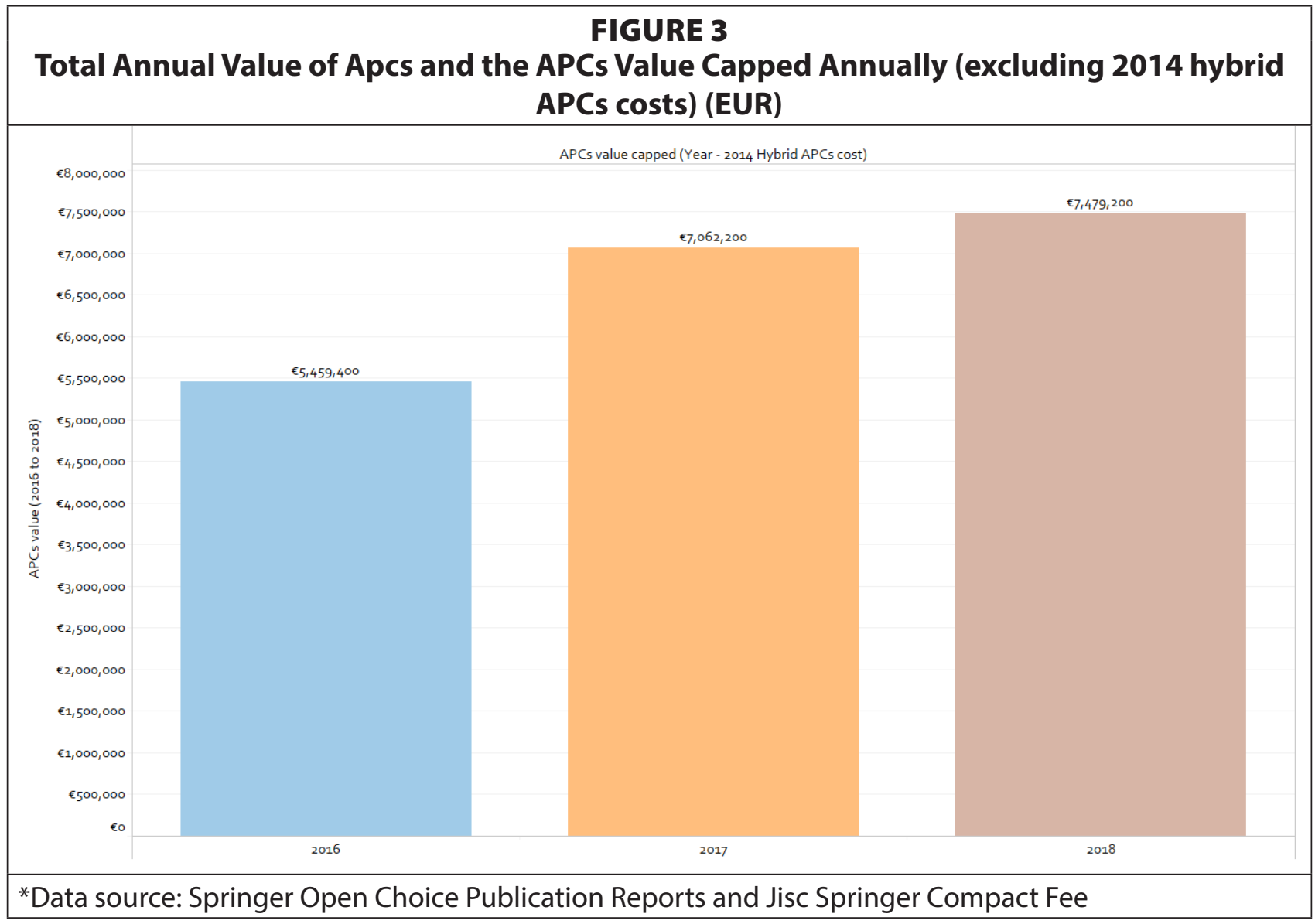


Because the APC cost in Euros remined constant, if an institution published more articles than in 2014, we can say that they have "capped" their costs by publishing more OA articles without incurring higher costs. Indeed, all institutions capped their 2014 APC costs. Figure 3 shows the total APCs value capped annually (that is to say, 2014 hybrid APCs cost was deducted from each year's APCs value, which is based on the number of OA articles published by all institutions in the agreement).

Some institutions not only capped their APC spend but have also published articles with a value over and above the combined fee. When subtracting the value of the total APCs published between 2016 and 2018 from the total combined fee paid by each institution, it was shown that 14 institutions have published APCs to a greater value than their total spend on the combined fee in all three years of the pilot. These institutions, which represent a broad cross-section of consortia membership including large research-intensive universities, medium-sized institutions and smaller specialist institutions have offset the cost of the agreement.

There was an additional group of institutions that started to offset their combined fee as the agreement progressed. Only 11 institutions published APCs to a greater value than their total spend on two years of the agreement, and 12 institutions avoided costs in one year of the agreement.

Furthermore, if the author opt-outs had been published OA, the total number of OA articles published, and the value of the offset/costs avoided could have been far higher. If all author opt-outs are included, 13,350 articles would have been published OA (instead of $10,905)$. This would have meant that 37 institutions would have offset the agreement and would have avoided costs of $€ 3,214,002(\$ 3,657,659)$ in spend (double their current $€ 1,657,788$ $[\$ 1,886,627]$ cost avoidance).

\section{Cost per Download (CPD)}

By definition, if a renegotiated agreement was to fully transition into a pay-to-publish model, the traditional method of working out CPD based on usage divided by subscription costs becomes redundant.

However, although many institutions have offset their costs, this is by no means the case for all. As part of the read-and-publish model, and in recognition that a percentage of articles within hybrid journals remain behind the subscription barrier, institutions continue to pay a "read fee." Even if an institution has not offset the total combined fee, the CPD provides an indication as to whether an institution is gaining value through a low CPD.

Table 6 shows the adjusted CPD (see Methodology section). Springer's 2017 adjusted CPD $(€)$ is significantly below any other major publishers CPD for UK consortia agreements (Figure 4). This is a potential benefit of read and publish models for less research-intensive institutions as they see an increase in value (measured by CPD) over a traditional subscription only agreement.

\begin{tabular}{|l|c|c|c|}
\hline \multicolumn{4}{|c|}{ TABLE 6 } \\
Adjusted CPD (2016 to 2018) \\
\hline & 2016 Adjusted CPD & 2017 Adjusted CPD & 2018 Adjusted CPD \\
\hline Maximum & $€ 2.32(\$ 2.64)$ & $€ 2.39(\$ 2.72)$ & $€ 2.15(\$ 2.45)$ \\
\hline Minimum & $€ 0.00(\$ 0.00)$ & $€ 0.00(\$ 0.00)$ & $€ 0.00(\$ 0.00)$ \\
\hline Average & $€ 0.46(\$ 0.52)$ & $€ 0.33(\$ 0.38)$ & $€ 0.24(\$ 0.27)$ \\
\hline Data sources: JUSP, Jisc Springer Compact Fee, and Springer Open Choice Publication Reports. \\
\hline
\end{tabular}




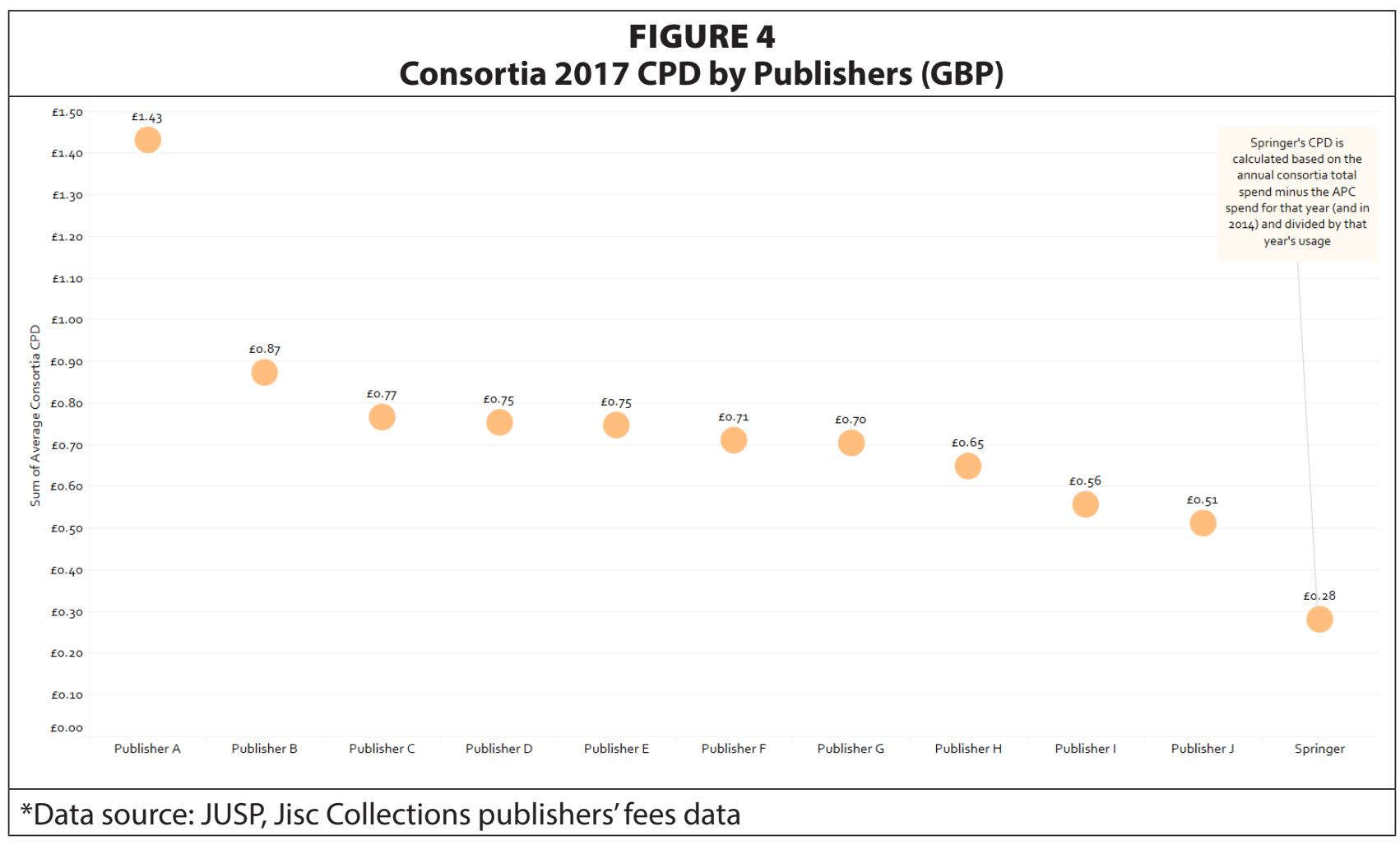

\section{Compliance with Funder Mandates}

Over the lifetime of the agreement, 99.97 percent of the OA articles were published under CC BY licenses. Therefore, the requirement of compliance with major research funders OA policies (COAF/Wellcome Trust, UKRI [RCUK], Research England [HEFCE], Horizon 2020, and others) was met by the agreement. It is also reasonable to assume that this agreement would also be compatible with cOAlition $S$ requirements for a transformational agreement. ${ }^{32}$

However, no further analysis was made on criteria such as ORCID data and funders' data because of the insufficient quality of the funder metadata. For example, it was found that the funders' data referred to the research funding source and not the article funding source and that not all funders had been identified and acknowledged by authors.

\section{Administration Efficiencies}

All articles were deposited in Jisc Publications Router ${ }^{33}$ by Springer, meaning that the gold version of the article was passed on to institutions to help them capture their research articles onto their repositories or current research information systems (CRIS). Furthermore, the simplicity of the process for authors and universities has been welcomed. ${ }^{34}$ This supports the Swedish findings. ${ }^{35}$

\section{Recommendations for Further Analysis}

Analysis of research presented in this article paints a broadly positive picture of Springer Compact as a pilot agreement, showing year-on-year improvements. However, there are also a number of key areas that require further consideration and discussion among the stakeholders involved.

The increase in the number of OA articles published by UK leading authors is encouraging. It is also encouraging to see the reduction in CPD for institutions. However, further 
investigation is required regarding the relationship between usage between the journals with the highest/lowest number of articles published and the usage data for the same titles for the whole consortium (including articles where authors opted out of $\mathrm{OA}$ ). This includes data on total annual downloads of UK-authored OA articles and the reach/impact of gold OA articles outside the UK to generate impact stories. This would allow the identification of titles that have high a) high OA content and high use, b) high OA content/low use, c) low OA content/ high use, and d) titles that are neither well used or published in. Altmetric data, which was investigated in the BIBSAM study, ${ }^{36}$ could also inform the reach of OA articles over non-OA.

The number of author opt-outs continues to lessen the ability to constrain costs. Although the number of opt-outs reduced, in financial terms this equates to $€ 5,379,000(\$ 6,121,511)$. In the $\mathrm{UK}$, opt-outs remain an issue and impact on the value of the agreement to individual institutions.

Although many institutions have either avoided additional APC costs or have offset the combined costs of the agreement, further analysis is required in estimating the number of institutions that might offset the entire Springer Compact agreement over time. For example, a number of institutions were between one and five articles away from offsetting the combined costs. This analysis will also assist in understanding whether some institutions may never offset the agreement. There is evidence in the data that suggests the 2014 APC calculations may have prevented at least one institution from doing so. However, the data also shows benefits across all types of institutions within the consortia. Therefore, even if an institution never flips the model, they may still benefit from the added value (such as reduced CPD) of being within the read and publish model.

Reporting that an institution or even a consortium has successfully flipped to a pay-topublish model is not enough. Any transition toward full and immediate OA needs to be at a global level. Therefore, further work at an international level is required to fully understand the transition to OA across all consortia and all Springer titles/disciplines, and the pace that this might happen to better inform the flipping point. This could be achieved by using data collected by OpenAPC ${ }^{37}$ to understand the number of authors publishing $\mathrm{OA}$ by title and discipline.

Furthermore, if multiple consortia flip their business models to OA, is this achieving the objectives of Plan S? Not if the journals remain hybrid to "nonsubscribers." There is a need to understand how to flip the full portfolio or a subset of titles to OA. There is no evidence from the pilot regarding Springer's criteria for flipping titles to OA. It is vital to understand the methodology behind how the "flip" point at which hybrid journals become fully OA is identified. Indeed, throughout the three years of the agreement, only two titles have flipped to OA (Environmental Health and Preventive Medicine and Gynaecological Surgery). The rationale behind this decision has not been disclosed.

It is also strongly recommended that Springer improve the quality of metadata on ORCID, funder name, and grant number by adopting ORCID for all authors and implement Crossref's Funders Registry in line with the ESAC recommendations for article workflows. ${ }^{38}$

Detailed financial analysis has had to be excluded from this analysis due to confidentiality. However, any further research on read-and-publish agreements needs to include a move toward increasing transparency in the way the costs are allocated to institutions in any future agreement.

The recommendations made above highlight some of the areas where further action is required and that would ultimately result in greater cost reduction and efficiencies. Most important, they are aligned with Plan S principles for transformative agreements. 


\section{Conclusion}

The analysis undertaken during the three years of the Springer Compact pilot has been extremely valuable to the consortia. It has provided a significant evidence base for all stakeholders to review and consider whether the pilot has achieved its aims of containing the total cost of publication, reducing administration barriers, increasing funder-compliant OA articles. The pilot has:

- Identified inefficiencies or issues that the stakeholders have been able to address together to improve data, administration, transparency, and value;

- Detected where further work or consideration is required by the stakeholders to improve the effectiveness of the model in transitioning to open access; and

- Enabled the UK to contribute data to the Open APC initiative and collaborate with other consortia who have supported a read-and-publish model to consider its ability to transform to a fully open access model.

The simplicity in the process for authors and universities has also been used as an exemplar for other UK agreements as well as the ESAC workflow requirements (with the exception of funder metadata). ${ }^{39}$

There is still much more that can be done. For example, Geschuhn and Stone observed that "[e]ven where publishing charges are used as the basis for an agreement, there are still many elements which relate to the subscription business, such as price increases, fixed article contingents, arbitrary growth rates and guarantee amounts. In addition to that, the current APC levels have not yet been challenged and discussed, for example, in terms of how they relate to production costs and services." 40

The pilot agreement has not resulted in a transition to full and immediate OA. During the three years of the pilot, only two journals in the portfolio have flipped from hybrid to full $\mathrm{OA}$; the reasons for this remain unknown. Without other countries and consortia adopting the same model, the Springer portfolio will remain hybrid. Plan S may assist with this issue as will the communication of the results of this analysis. Further work with other consortia and OpenAPC will shed more light on this area.

On a unilateral level, almost 75 percent of the UK research published in the eligible journals in 2018 is now published OA, and this could increase to 85 percent if opt-outs are converted to OA. To achieve 100 percent, the issue of publication in noneligible titles, which accounted for 14.6 percent (2,353 articles) between 2016 and 2018, needs to be addressed. These titles need to be brought into future agreements.

The evidence presented in this article is helping to inform ongoing discussions with institutions, funders, and Springer as to the effectiveness of this model in realizing a transition to $\mathrm{OA}$, the ability to constrain costs, and the movement away from models based on print spend to models based on publication. It will also contribute to discussions with other publishers regarding the transition to OA in support of UK funders' commitment to cOAlition S.

In April 2019, it was announced that Jisc and Springer Nature had renewed the Compact agreement for a further three years (2019-2021). ${ }^{41}$

\section{Acknowledgments}

The authors would like to thank our colleagues Caren Milloy and Anna Vernon at Jisc for their comments and support regarding on this article and earlier drafts of the internal report. 


\section{Notes}

1. Kai Geschuhn and Graham Stone, "It's the Workflows, Stupid! What Is Required to Make 'Offsetting' Work for the Open Access Transition," Insights 30 (2017): 103-14, https://doi.org/10.1629/uksg.391.

2. Bo-Christer Björk, "Scholarly Journal Publishing in Transition: From Restricted to Open Access," Electronic Markets 27(2017): 1-9, https://doi.org/10.1007/s12525-017-0249-2.

3. Stuart Lawson, "Total Cost of Ownership of Scholarly Communication: Managing Subscription and APC Payments Together," Learned Publishing 27 (2015): 13, https://dx.doi.org/10.1087/20150103.

4. Stuart Lawson, "Evaluating UK Offset Agreements (2015-2017)," published online June 25, 2019, https:// dx.doi.org/10.5281/zenodo.3256643.

5. Ralf Schimmer, Kai Karin Geschuhn, and Andreas Voglerm, Disrupting the Subscription Journals' Business Model for the Necessary Large-scale Transformation to Open Access (München, Germany: MPDL, 2015), https://doi. org/10.17617/1.3.

6. Liam Earney, "National Licence Negotiations Advancing the Open Access Transition: A View from the UK," Insights 31 (2018): 11, http://doi.org/10.1629/uksg.412; Anna Lundén, Camilla Smith, and Britt-Marie Wideberg, "National Licence Negotiations Advancing the Open Access Transition: A View from Sweden," Insights 31 (2018): 12, http://doi.org/10.1629/uksg.413; Rita Pinhasi et al., "The Weakest Link: Workflows in Open Access Agreements: The Experience of the Vienna University Library and Recommendations for Future Negotiations," Insights 31 (2018): 27, http://doi.org/10.1629/uksg.419.

7. Liam Earney, "Offsetting and Its Discontents: Challenges and Opportunities of Open Access Offsetting Agreements," Insights 30 (1: 2017): 11-24, https://doi.org/10.1629/uksg.345.

8. Lawson, "Evaluating UK Offset Agreements (2015-2017)."

9. Science Europe, "Principles and Implementation," https://www.coalition-s.org/principles-and-implementation/ [accessed 22 August 2019].

10. Earney, "National Licence Negotiations Advancing the Open Access Transition."

11. Katie Shamash, Article Processing Charges (APCs) and Subscriptions: Monitoring Open Access Costs (Bristol, UK: Jisc, 2016), https://www.jisc.ac.uk/sites/default/files/apc-and-subscriptions-report.pdf.

12. Katie Shamash, "Article Processing Charges in 2016," Jisc Scholarly Communications (blog, August 23, 2017), https://scholarlycommunications.jiscinvolve.org/wp/2017/08/23/article-processing-charges-in-2016/.

13. MIT Libraries, "MIT and RSC Sign First North American 'Read and Publish' Agreement," MIT Libraries (blog, June 19, 2018), https://libraries.mit.edu/scholarly/2018/spotlight-mit-and-rsc-sign-first-north-american-readand-publish-agreement/.

14. University of California, Office of Scholarly Communication, "Negotiating with Scholarly Publishers: A Toolkit from the University of California," https://osc.universityofcalifornia.edu/open-access-at-uc/publishernegotiations/negotiating-with-scholarly-journal-publishers-a-toolkit/ [accessed 21 August 2019].

15. Springer, "Open Access Agreement for UK Authors," https://www.springer.com/gp/open-access/springeropen-choice/springer-compact/agreements-uk-authors [accessed 21 August 2019].

16. Jisc, "Springer: Jisc Collections:Compact:2016-2018," https://www.kbplus.ac.uk/kbplus7/publicExport/ pkg/1483 [accessed 21 August 2019].

17. OpenAPC, "Springer Compact Coverage," https://treemaps.intact-project.org/apcdata/springer-compactcoverage/\#publisher/ [accessed 22 August 2019].

18. Mafalda Marques, "Offsetting Models: Update on the Springer Compact Deal," Jisc Scholarly Communications (blog, October 24, 2016), https://scholarlycommunications.jiscinvolve.org/wp/2016/10/24/offsetting-models-updateon-the-springer-compact-deal/; Mafalda Marques, "Findings from Institutional Survey on the Springer Compact Agreement," Jisc Scholarly Communications (blog, July 12, 2017), https://scholarlycommunications.jiscinvolve.org/ wp/2017/07/12/institutions-survey-on-the-springer-compact-agreement/.

19. Ulf Kronman, Evaluation of Offset Agreements-Report 3: Springer Compact (Stockholm: National Library of Sweden, 2018), https://www.kb.se/download/18.2705879d169b8ba882a5560/1556566760356/Evaluation_of_offset_ agreements_SC_Report_3.pdf; Lisa Olsson, Evaluation of Offset Agreements-Report 4: Springer Compact (Stockholm: National Library of Sweden, 2018), https://www.kb.se/download/18.2705879d169b8ba882a5561/1556566760424/ Evaluation_of_offset_agreements_SC_Report_4-20181008.pdf.

20. Springer Nature, "Adis," https://www.springer.com/gp/adis [accessed 9 December 2019].

21. Equivalent in USD at the exchange rate of 1.138038889, which was the monthly average for December 2018. Data source: Federal Reserve, "Foreign Exchange Rates," https://www.federalreserve.gov/releases/H10/ hist/dat00_eu.htm [accessed 9 December 2019].

22. Jisc, "Journal Usage Statistics Portal," https://jusp.jisc.ac.uk/ [accessed 22 August 2019].

23. COUNTER, "The COUNTER Code of Practice for Release 4: Usage Reports," https://www.projectcounter. 
org/code-of-practice-sections/usage-reports/ [accessed 9 December 2019]. Note: The Code of Practice Release 4 has now been superseded by Release 5 .

24. OpenAPC, "Springer Compact Coverage."

25. ESAC, "Agreement Registry," https://esac-initiative.org/about/transformative-agreements/agreementregistry/ [accessed 22 August 2019].

26. “ROARMAP," http://roarmap.eprints.org/view/country/826.html [accessed 21 August 2019].

27. Marques, "Findings from Institutional Survey on the Springer Compact Agreement."

28. Olsson, Evaluation of Offset Agreements-Report 4: Springer Compact.

29. Stephen Pinfield, Jennifer Salter, and Peter A. Bath, “The 'Total Cost of Publication' in a Hybrid OpenAccess Environment: Institutional Approaches to Funding Journal Article-Processing Charges in Combination with Subscriptions," Journal of the Association for Information Science and Technology 67 (2016): 1751-66, https:// dx.doi.org/10.1002/asi.23446.

30. The only exception to the $€ 2,200$ ( $\$ 2,504)$ APC cost was the European Physical journals collection, which was $€ 1,200(\$ 1,366)$ in $2016-2017$ and $€ 1,800(\$ 2,048)$ in 2018 . However, only a small number of OA articles were published here, 117 articles in total $(€ 181,000)(\$ 205,985)$.

31. The method applied to determine the exchange rate date was based on selecting the first day after the end of the reporting period. For January 1 to December 31, 2016, the first day an exchange rate was available was January 3, 2017. The Bank of England Euro exchange for 3 January 2017 was 1.1786. The exchange rate on January 2, 2018 was 1.1274. The exchange rate on January 2, 2019 was 1.1104.

32. Science Europe, "Principles and Implementation."

33. Jisc, "Publications Router," https://pubrouter.jisc.ac.uk/ [accessed 22 August 2019].

34. Frank Manista, "Off-Setting Workshops: Helping Universities Get the Most from the Deals," Jisc Scholarly Communications (blog, August 5, 2016), https://scholarlycommunications.jiscinvolve.org/wp/2016/08/05/jisc-offsetting-workshops-helping-universities-get-the-most-from-the-deals/.

35. Olsson, Evaluation of Offset Agreements-Report 4: Springer Compact.

36. Olsson, Evaluation of Offset Agreements-Report 4: Springer Compact.

37. OpenAPC, "Springer Compact Coverage."

38. Geschuhn and Stone, "It's the Workflows, Stupid!"

39. "Efficiency and Standards for Article Charges (ESAC)", http://esac-initiative.org/ [accessed 21 August 2019]; Geschuhn and Stone, "It's the Workflows, Stupid!"

40. Geschuhn and Stone, "It's the Workflows, Stupid!"

41. "Jisc and Springer Nature Renew Transformational Deal Securing Open Access for UK Higher Education," Jisc News (blog, April 26, 2019), https://www.jisc.ac.uk/news/jisc-and-springer-nature-renew-transformationaldeal-26-apr-2019. 